\title{
Metode Braistorming Tertulis: Teknik Curah Pendapat Dengan Memaksimalkan Keterlibatan Semua Peserta Dalam Pengambilan Keputusan
}

\section{Drs. Yusuf. M.Pd 1, Dr. Anita Trisiana, M.Hum 2 1 yusuf.unisri29@gmail.com \\ 2 anita.trisiana@gmail.com}

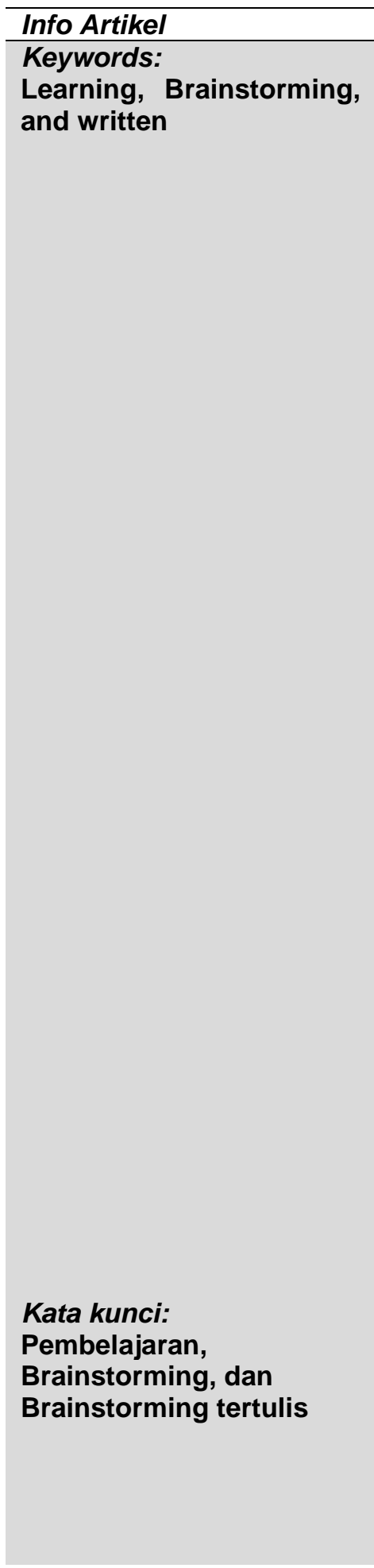

\begin{abstract}
The brainstorming method is also known as the brainstorming or brainstorming method. It's just that this time the brainstorm is done in writing. Not verbally. In contrast to the discussion, where the ideas of a person can be responded to (supported, supplemented, reduced, or disagreed) by other participants, the brainstorming method of using other people's opinions is not to be responded to. This method is based on the opinion that a group of people can submit more proposals than their respective members. In this method a problem is presented. Then the participants were invited to submit any ideas about the matter, no matter how strange the ideas were. Strange ideas are not rejected a priori, but are analyzed, synthesized and evaluated. It could be an unexpected solution that finally appeared ". Thus it can be concluded that the Brainstorming method is a form of discussion in which participants are encouraged to express ideas, opinions, information, knowledge, experience and ideas about a problem without any assessment of the participants. It's just that the brainstorming that you are trying to introduce is written. The purpose of using the Brainstorming method is to "completely drain everything that is thought by students in addressing the problems posed to him". So that the objectives in applying the Brainstorming method can be achieved, it is necessary to have rules that are considered. This is intended so that the Brainstorming method can run effectively and efficiently so that the expected goals can be realized.
\end{abstract}

\footnotetext{
Abstrak

Metode Brainstorming dikenal juga dengan metode curah pendapat atau sumbang saran. Hanya saja brainstorming kali ini dialakukan dengan cara tertulis. Tidak secara lisan. Berbeda dengan diskusi, dimana gagasan dari seseorang dapat ditanggapi (didukung, dilengkapi, dikurangi, atau tidak disepakati) oleh peserta lain, pada penggunaan metode Brainstorming pendapat orang lain tidak untuk ditanggapi. Metode ini berdasarkan pendapat bahwa sekelompok manusia dapat mengajukan usul
} 
lebih banyak dari anggotanya masing-masing. Dalam metode ini disajikan sebuah soal. Lalu para peserta diajak untuk mengajukan _dea pa pun mengenai soal itu, tidak peduli seaneh apapun ide itu. Ide-ide yang aneh tidak ditolak secara apriori, tetapi dianalisis, disintesis dan dievaluasi. Boleh jadi pemecahan yang tidak terduga yang akhirnya muncul". Dengan demikian dapat disimpulkan bahwa metode Brainstorming adalah suatu bentuk diskusi dimana peserta didorong untuk menyatakan gagasan, pendapat, informasi, pengetahuan, pengalaman serta ide-ide mengenai suatu masalah tanpa adanya penilaian dari pesertalain. Hanya saja brainstorming yang dicoba dikenalkan adalah dengan cara tertulis. Tujuan penggunaan metode Brainstorming ialah "menguras habis segala sesuatu yang dipikirkan oleh peserta didik dalam menggapi masalah yang dilontarkan kepadanya". Agar tujuan dalam penerapan metode Brainstorming dapat tercapai maka perlu adanya aturan yang diperhatikan. Hal ini dimaksudkan agar metode Brainstorming dapat berjalan dengan efektif dan efisien sehingga tujuan yang diharapkan dapat terealisasi.

\section{PENDAHULUAN}

Kita sadari bahwa dalam proses pembelajaran ada adagium bahwa tida ada satupun metode yang paling baik. Begitu juga sebaliknya, tidak ada satupun metode pembelajaran yang paling buruk. Baik buruknya suatu metode banysak ditentukan oleh factor factor yang melingkupi proses pembelajaran.

Bisa jadi suatru metode itu akan sangat baik dan efektif digunakan oleh seorang guru unttuk mengajarkan materi tertentu pada peserta didik tertentu. Akan tetapi, metode yang efektif untuk guru tersebut, belum tentu efektif digunakan olkeh guru lain untuk mengajar kelas dan materi yang sama bagi guru yang sangat efektif kmenggunakan metode tersebut.

Karena itu, pemilihan metode harus memperhatikan keberadaan para pihak yang terkait dalam proses pembelajaran tersebut. Para pihak tersebut seperti guru, peserta didik, pokok kajian yang dikaji, lingkungan belajar peserta didik, sarana dan prasarana pembelajaran, kurikulum, kepemimpinan sekolah, lingkungan domistik sekolah, lingkungan internasional sekolah dan sebagainya. Ketepatan merancang proses pembelajaran dalam suatu lingkungan sekolah tertentu, akan sangat membantu dalam menyelenggarakan proses pembelajaran yang maksimal.

\section{METODE PEMBELAJARAN}

Metode merupakan suatu cara yang dipergunakan untuk mencapai tujuan yang telah ditetapkan. "Metode merupakan proses belajar dan pembelajaran yang merupakan interaksi yang dilakukan antara guru dengan peserta didik dalam suatu proses pembelajaran untuk mewujudkan tujuan yang ditetapkan".Abdul Majid (2011:135). Menurut Edgar dan Stanley (1995:339) mengemukakan bahwa "study method is with refer toing activity instructed by teacher and result him is activity learn at student". (Edgar dan Stanley, 995:339). Artinya, metode pembelajaran 
adalah serangkaian kegiatan yang diarahkan oleh guru dan hasilnya adalah kegiatan belajar pada peserta didik.

Metode mengajar merupakan suatu pengetahuan tentang cara-cara mengajar yang dipergunakan untuk seorang guru atau instruktur. Teknik penyajian yang dikuasai guru untuk mengajar atau menyajikan bahan pelajaran kepada peserta didik di dalam kelas, baik secara individual atau secara kelompok/klasikan, agar pelajaran itu dapat diserap, dipahami dan dimanfaatkan oleh peserta didik dengan baik. Makin baik metode mengajar, makin efektif pula pencapaian tujuan.(Abu Ahmadi dan Joko Tri Prasetyo ,2005: 52)Sejalan pendapat diatas ,Nana Sudjana, (1998: 76) menegaskan bahwa "Metode mengajar adalah cara atau serangkaian kegiatan yang dipergunakan guru dalam mengadakan hubungan dengan peserta didik pada saat berlangsungnya pembelajaran". Oleh karena itu peranan metode pembelajaran sebagai alat untuk menciptakan proses mengajar dan belajar. Dengan metode ini diharapkan tumbuh berbagai kegiatan belajar peserta didik berkaitan dengan kegiatan mengajar guru.Jadi dapat disimpulkan bahwa metode mengajar adalah serangkaian kegiatan yang dipergunakan oleh guru agar pelajaran itu dapat diserap, dipahami dan dimanfaatkan oleh peserta didik untuk mewujudkan tujuan pembelajaran yang telah ditetapkan.Menurut Syaiful Bahri Djamarah dan Aswan Zain (2010:72) metode dalam pengajaran memiliki beberapa kedudukan, yaitu:

a. Metode sebagai alat motivasi ekstrinsikMotivasi ekstrinsik. Sadirman. A.M (dalam Syaiful Bahri Djamarah dan Aswan Zain 2010:73) adalah bahwa motif-motif yang aktif dan berfungsinya, karena adanya perangsang dari luar. Karena itu, metode berfungsi sebagai alat perangsang dari luar yang dapat membangkitkan belajarseseorang.

b. Metode sebagai strategi pengajaran, Menurut Roestiyah. N.K (dalam Syaiful Bahri Djamarah dan Aswan Zain 2010:74) dalam kegiatan belajar dan pembelajaran guru harus memiliki strategi agar anak didik dapat belajar secara efektif dan efisien, mengena pada tujuan yang diharapkan. Salah satu langkah untuk memiliki strategi adalah harus menguasai teknik-teknik penyajian atau biasanya disebut metode mengajar.

c. Metode sebagai alat untuk mencapai tujuanMenurut Syaiful Bahri Djamarah dan Aswan Zain (2010:74) tujuannya adalah untuk mencapai suatu cita-cita yang akan dicapai dalam kegiatan belajar dan pembelajaran. Metode adalah salah satu alat untuk mencapai tujuan. Sehingga dengan memanfaatkan metode secara akurat, guru akan mampu mencapai tujuan pengajaran.

Dari uraian di atas dapat disimpulkan bahwa guru sebagai pengajar, instruktur atau apalagi sebagai fasilitator, sebaiknya menggunakan metode yang dapat menunjang kegiatan belajar dan pembelajaran, sehingga dapat dijadikan sebagai alat yang efektif untuk mencapai tujuan pengajaran.

\section{METODE BRAINSTORMING}

Metode Brainstorming dikenal juga dengan metode curah pendapat atau sumbang saran. "Metode Brainstorming adalah suatu bentuk diskusi dalam rangka menghimpun gagasan, pendapat, 
informasi, pengetahuan, pengalaman, dari semua peserta".(M. Sobry Sutikno, 2007:98): Berbeda dengan diskusi, dimana gagasan dari seseorang dapat ditanggapi (didukung, dilengkapi, dikurangi, atau tidak disepakati) oleh peserta lain, pada penggunaan metode Brainstorming pendapat orang lain tidak untuk ditanggapi. Metode ini berdasarkan pendapat bahwa sekelompok manusia dapat mengajukan usul lebih banyak dari anggotanya masing-masing. Dalam metode ini disajikan sebuah soal. Lalu para peserta diajak untuk mengajukan ide apa pun mengenai soal itu, tidak peduli seaneh apa pun ide itu. Ide-ide yang aneh tidak ditolak secara apriori, tetapi dianalisis, disintesis dan dievaluasi juga. Boleh jadi pemecahan yang tidak terduga yang akhirnya muncul". "Brainstorming adalah salah satu bentuk berpikir kreatif sehingga pertimbangan memberikan jalan untuk berinisiatif kreatif. Peserta didorong untuk mencurahkan semua ide yang timbul dari pikirannya dalam jangka waktu tertentu berkenaan dengan beberapa masalah, dan tidak diminta untuk menilainya selama curah pendapat berlangsung. Penilaian akan dilakukan pada periode berikutnya dimana semua ide dipilih, dievaluasi dan mungkin diterapkan".(Suprijanto, 2009:122) Sejalan dengan itu Kang dan Song (dalam 2009 :122) "metode Brainstorming adalah teknik diskusi kelompok dimana anggotanya menyatakan sebanyak mungkin ide-idenya atas topik tertentu tanpa hambatan dan pertimbangan aplikasi praktisnya. Spontanitas dan kreativitas merupakan bagian penting dalam curah pendapat penilaian terhadap ide-ide dilakukan pada sesi berikutnya". Menurut Barbara Allman dan Sara Freeman (2010:37) "Brainstorming adalah suatu teknik yang digunakan untuk menghasilkan suatu daftar panjang yang berisi berbagai respon berbeda tanpa membuat penilaian terhadap ide-ide individu".(Barbara Allman dan Sara Freeman , 2010:37)

Dengan demikian dapat disimpulkan bahwa metode Brainstorming adalah suatu bentuk diskusi dimana peserta didorong untuk menyatakan gagasan, pendapat, informasi, pengetahuan, pengalaman serta ide-ide mengenai suatu masalah tanpa adanya penilaian dari pesertalain. Tujuan penggunaan metode Brainstorming ialah "menguras habis segala sesuatu yang dipikirkan oleh siswa dalam menggapi masalah yang dilontarkan guru kepadanya".(M. Subana ,2009:106). Agar tujuan dalam penerapan metode Brainstorming dapat tercapai maka perlu adanya aturan yang diperhatikan. Hal ini dimaksudkan agar metode Brainstorming dapat berjalan dengan efektif dan efisien sehingga tujuan yang diharapkan dapat terealisasi.

Hanya saja prosedur barainstorming ini, dalam pelaksanaannya didahului dengan curah pendapat secara tertulis dengan menggunakan kartu yang telah dituangkan nide pemecahan masalah yang sudah tertulis,

Menurut Utami Munandar (1985:104) beberapa aturan yang harus perhatikan pada metode Brainstorming adalah:

a. Kebebasan dalam memberikan gagasan

Peserta didik tidak perlu merasa ragu-ragu untuk mengeluarkan gagasan apa pun, yang "aneh" atau "yang lain dari yang lain". la pun tidak perlu merasa terikat pada apa yang sudah berlaku sampai sekarang, pada kebiasaan-kebiasaan yang lama. 
b. Penekanan pada kuantitas

Pada teknik Brainstorming diinginkan gagasan-gagasan sebanyak mungkin, karena dengan makin banyaknya gagasan makin besar pula kemungkinan bahwa di antara gagasan-gagasan tersebut ada yang sangat baik dan orisinil.

c. Kritik ditangguhkanSelama tahap pengungkapan gagasan, kritik baik oleh anggota maupun oleh ketua tidak boleh dibenarkan. Kritik baru dapat dikemukakan setelah tahap pencetusan gagasan selesai. Sesudah tahap ini ada tahap penilaian gagasan, di mana semua gagasan yang telah dicatat ditinjau satu per satu kemudian dipilih gagasan-gagasan yang terbaik.

d.Kombinasi dan peningkatan gagasanSiswa dapat menambahkan atau meneruskan gagasangagasan yang sebelumnya telah diungkapkan oleh siswa lain. Beberapa gagasan dapat digabung menjadi satu gagasan yang lebihbaik.

e. Mengulang gagasan yang tampaknya sama tidak menjadi soal, karena dalam kenyataan mungkin gagasan-gagasan tersebut agak berbeda. Teguran bahwa gagasan itu sudah disampaikan sebelumnya akan menghambat spontanitas siswa dalam mengungkapkan gagasan. Lagi pula apabila memang ada gagasan-gagasan yang sama, pada tahap penilaian gagasan tersebut dapat dikeluarkan.

\section{KELEBIHAN DAN KELEMAHAN METODE BRAINSTORMING.}

Pada dasarnya tiap metode yang digunakan dalam kegiatan pembelajaran memiliki kelebihan maupun kekurangan masing-masing. Kelebihan dapat digunakan sebagai acuan dalam pelaksanaan metode pembelajaran tersebut sedangkan kekurangan dapat dijadikan acuan agar metode pembelajaran itu dapat berjalan dengan lebih baik lagi.Acep Yonny dan Sri Rahayu Yunus (2011:127) menyatakan beberapa kelebihan dari penerapan metode Brainstorming sebagaiberikut:
a. Memberikan kesempatan peserta didik untuk berpendapat
b. Melatih daya kritis dan analisis peserta didik
c. Mendorong peserta didik agar dapat menghargai pendapat orang lain
d. Menstimulasi peserta didik agar dapat berpikir secara holistik.

Di sisi lain, Roestiyah (2012:74) menegaskan kelebihan metode Brainstrorming sebagai berikut:
a. Peserta didik aktif berfikir untuk menyatakan pendapat.
b. Melatih peserta didik berpikir dengan cepat dan tersusun logis.
c. Merangsang peserta didik untuk selalu siap berpendapat yang berhubungan dengan masalah yang diberikan oleh guru.
d. Meningkatkan partisipasi peserta didik dalam menerima pelajaran.
e. peserta didik yang kurang aktif mendapat bantuan dari temannya yang pandai atau dari guru.
f. Terjadinya persaingan yang sehat. 
g. Peserta didik merasa bebas dan gembira.

h. Suasana demokrasi dan disiplin dapat ditumbuhkan.

Walaupun teknik ini baik dan memiliki kelebihan tetapi juga mempunyai kelemahan. Menurut Suprijanto (2009:125) ada beberapa kelemahan dari penggunaan metode Brainstorming yang digunakan dalam mengambil keputusan, apalagi untuk pembelajaran:

a. Proses ini memerlukan banyak waktu, khususnya apabila kurang dari $10 \%$ ide yang akhirnya digunakan.

b. Seperti kelompok diskusi yang lain, produktivitas sesi curah pendapat tergantung pada kemampuan dan kualitas orientasi peserta.

c. Manfaat akhirnya mungkin lebih berupa apa yang dilakukan terhadap peserta daripada produktivitas apa yang segera diperoleh dalam sesi curah pendapat, dan sulit diukur dengan tingkat keakuratan apa pun.

Roestiyah (2012:75) berpendapat bahwa untuk mengatasi beberapa kelemahan metode Brainstorming bias dilakukan sebagai berikut:

Guru kurang memberi waktu yang cukup kepada peserta didik untuk berpikir dengan baik.

b. Peserta didik yang kurang selalu ketinggalan.

c. Kadang-kadang pembicaraan hanya dimonopoli oleh peserta didik yang pandai saja.

d. Guru hanya menampung pendapat tidak pernah merumuskan kesimpulan.

e. Peserta didik tidak segera tahu apakah pendapatnya itu betul/salah.

f. Masalah bisa berkembang ke arah yang tidak diharapkan.

Untuk mengatasi kelemahan Brainstorming lisan itulah maka pada kesempatan ini ditawarkan model brainstorming tertulis. Dengan brainstorming tertulis dengan memanfaatkan kartu sebagai media tulisnya, semua peserta didik terlibat dalam proses kegiatan curah pendapatat.

\section{METODE PELAKSANAAN}

\section{Waktu Pelaksanaan}

Pelaksanaan Pelatihan bagi para pengurus OSIS SMA Negeri 8 Surakarta adalah antara tagal 6 hingga 10 Desember 2019.

2. Lama pelaksanaan pelatihan

a. Persiapan dan koordinasisi dengan pihak wakil kepala sekolah dan Ketua OSIS dimulai pada bulan Nopember 2019.

b. Pelasanaan direncanakan berdasar kesepakatan pada tanggal 10 Desember 2019

c. Lama pelatihan diperkirakan selama $5 \mathrm{Jam}$.

d. Tempat pelaksanaan di Aula SMA Negeri 8 Surakarta

e. Alat dan bahan yang diperlukan adalah: 


\subsection{Spidol}

1.2. Potongan kertas buffalo

1.3. Selotip bolak balik

1.4. Lem

1.5. Papan tulis

1.6. Lap top

1.7. LCD

1.8. Sound system

\section{PROSEDUR BRAINSTORMING TERTULIS}

Prosedur yang bisa ditempuh dalam pelaksanaan brainstorming tertulis adalah:

1.1. Langkah pertama:
a. Menyiapkan kartu ukuran sekitar $15 \times 20 \mathrm{~cm}$ sejumlah peserta kali 3
b. Meniapkan spidol
c. Menyiapkan solatip bolak balik
d. Menyiapkan papan tulis dan sejenisnya

1.2. Langkah kedua
a. Membagikan kartu kepada semua peserta masing masing 3 lembar
b. Memberikan spidol secukupnya
c. Memberikan contoh menulis ide di kartu yang dibagi agar tulisan bias terbaca

\subsection{Langkah ketiga}
a. Memberikan judul permasalahan yang akan dipecahkan
b. Setiap peserta agar membuat pernyataan pada setiap kartu untuk memecahkan maslah
c. Panjang pernyataan maksimal 4 kata
d. Dalam pernyataan tidak ada kata sambung
e. Setelah selesai membuat pernyataan, pernyataan ditempel bebas di papan

1.4. Langkah keempat
a. Kelompokan pernyataan sejenis
b. Setelah mengelompok, beri judul di atas kelompok pernyataan

1.5. Langkah kelima Pembahasan ide per kelompok hasil brainstorming 


\section{HASIL DAN PEMBAHASAN}

Bahwa pelaksanaan pengabdian pada masyarakat yang mengambil sasaran Pengurus OSIS SMA Negeri 8 Surakarta, bisa dikatakan bisa terlaksana dengan baik. Indikatornya semua pengurus OSIS ikut dan terlibat dalam proses pelatihan tentang brainstorming tertulis.

Bagi pengurus OSIS, pelaksanaan brainstorming tertulis merupakan ppengalaman baru dalam model pengambilan keputusan dalam suatu organisasi. Brainstorming yang selama ini dikenalkan adalah brainstorming atau curah pendapat yang diikuti oleh peserta didik di kelas, tetapi hanya diikuti oleh beberapa orang yang mau menyumbang pendapat dan pikiran. Peserta lainnya, pada umumnya tidak terlibat secara aktif dalam memberikan sumbangan p-emikiran dan pendapat.

Akan tetapi, begitu dikenalkan dengan metode Brainstorming tertulis, semua peserta terlibat dan memberiikan sumbang saran pemikirang yang dituangkan dalam kartu yang telah dibagikan kepada semua anggota pengurus OSIS. Peserta semua berpendapat. Baik pendapat yang dianggap bermutu hingga pendapat yang dianggap paling tidak bermutu. Semua pendapat dipaparkan di papan tulis, kemudian dikelompokan ke dalam pendapat sejenis, setelah itu pendapat sejenis diberi judul masalah. Dan, semua itu mencerminkan pendapat semua anggota pengurus OSIS tanpa kecuali.

Setelah semua pendapat dikelompokan baru dibahas bersama oleh semua pengurus OSIS. Dengan demikian tidak ada orang yang tidak berpendapat. Semua berpendapat. Semua ikut berfikir dan berembuk. Akhirnya semua ikut mengambil keputusan bersama.

Model brainstorming tertulis ini, bagi yang sering bergaul dengfan aktifis LSM, bukan hal yang baru. Tetapi hal yang biasa mereka gunakan untuk mengambil keputusan dengan memaksimalkan partisipasi aktif semua peserta. Dan bagi Pengurus OSIS, merupakan sesuatu yang baru bagi mereka.

\section{PENUTUP}

Dengan metode brainstorming tertulis ini, dipastikan bahwa kekhawatiran kalua pelaksanaan metode brainstorming hanya akan didominasi oleh peserta didik yang aktif dan berani berbicara akan bisa dihindari. Mengapa demikian, denga $\mathrm{n}$ brainstorming tertulis semua peerta telah diberi kesempatan sama dan tinggal menuangkan gagasannya di kertas berupa kartu yang telah dibagikan. Kesempatan beratrgumentasi juga diberikan kalua pendapatnya diipersoalkan.

Branstorming tertulis tertulis ini akan sangat berguna untuk mengajarkan proses berdemokrasi yang bias diikuti oleh semua orang. Dengan demikian pengamalan sila Kerakyatan yang dipimpin oleh hikmah kebijaksanaan dalam permusyawaratan/ perwakilan bias dilaksanakan.. Konteks musyawarah bisa berjalan dengan partisipasi semua peserta. 


\section{REFERENCES}

Allman Barbara dan Freeman S. , Menjadi Guru Kreatif. Golden Book, Jogjakarta, 2010

B. Uno Hamzah, Perencanaan Pembelajaran. PT. Bumi Aksara, Jakarta, 2010

Dananjaya, Utomo, Media Pembelajaran Aktif. Nuansa. Bandung, 2012

Djamarah, S.B dan Zain, AStrategi Belajar Mengajar. Rineka Cipta, Jakarta, 2010

Fathurrohman. P dan Sobry, S., Strategi Belajar Mengajar. PT. Refika Aditama,Bandung, 2007

Madjid, A, Perencanaan Pembelajaran. Remaja Rosdakarya, Bandung, 2011

Munandar, Utami, Mengembangkan Bakat dan Kreativitas Anak Sekolah. PT. Gramedia. Jakarta, 1985

Nurdin, Syafrudin., Model Pembelajaran Dengan Memperhatikan Keberagaman, 2004

Individu Siswa Dalam Kurikulum Berbasis Kompetensi. Remaja Rosdakarya,Bandung

Roestiyah N.K., Strategi Belajar Mengajar. PT. Rineka Cipta.Jakarta, 2012

Soebani, B. A, Perencanaan Pembelajaran. Remaja Rosdakarya. Bandung, 2008

Subana dan Sunarti, Strategi Belajar Mengajar Bahasa Indonesia. CV Pustaka Setia. Bandung, 2009.

Sudjana, N, Dasar-Dasar Proses Belajar Mengajar. Sinar Baru Algesindo, Bandung, 1998

Suprijanto, Pendidikan Orang Dewasa. PT. Bumi Aksara. Jakarta, 2009

Supriyadi Strategi Belajar Mengajar. Cakrawala IImu, Yogyakarta, 2011

Surjadi, A, Membuat Siswa Aktif Belajar. Mandar Maju, Bandung, 1989

Trianto, Mendesain Model Pembelajaran Inovatif - Progresif. Kencana, Jakarta, 2009

-,Model Pembelajaran Terpadu. Bumi Aksara. Jakarta, 2012 